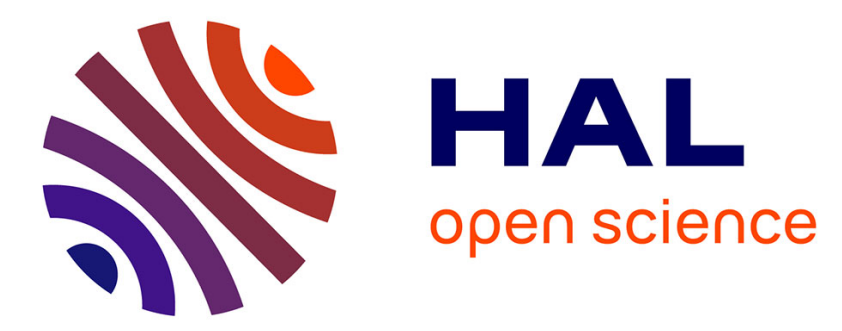

\title{
Researchers on display: moving the laboratory into the museum
}

Morgan Meyer

\section{To cite this version:}

Morgan Meyer. Researchers on display: moving the laboratory into the museum. Museum Management and Curatorship, 2011, 26 (3), pp.261-272. 10.1080/09647775.2011.585800 . hal-00603763

\section{HAL Id: hal-00603763 \\ https: / hal-mines-paristech.archives-ouvertes.fr/hal-00603763}

Submitted on 4 Mar 2013

HAL is a multi-disciplinary open access archive for the deposit and dissemination of scientific research documents, whether they are published or not. The documents may come from teaching and research institutions in France or abroad, or from public or private research centers.
L'archive ouverte pluridisciplinaire HAL, est destinée au dépôt et à la diffusion de documents scientifiques de niveau recherche, publiés ou non, émanant des établissements d'enseignement et de recherche français ou étrangers, des laboratoires publics ou privés. 


\title{
Researchers on display: moving the laboratory into the museum
}

\author{
Morgan Meyer \\ Centre de Sociologie de l'Innovation, Mines ParisTech
}

\begin{abstract}
An intriguing development is taking place in several European science museums: the move of university research laboratories into the space accessible to visitors. Seen as a means to encourage the public understanding of research and to render research practice more accessible to visitors, such laboratories-in-the-museum have been set up in museums in Munich, Berlin, Milan and Gothenburg. This paper is concerned with the changes that the laboratory undergoes through this relocation namely a transformation of its social and material architecture; an extension of its object-world; and a change in, and multiplication of, the roles of researchers. The laboratory-in-the-museum not only represents, displays and explains a particular kind of space - the laboratory - but it is also designed to create space for dialogue and discussion between researchers and visitors.
\end{abstract}

\section{Keywords}

science museums, laboratory-in-the-museum, Deutsches Museum, open research laboratory, public understanding of research, nanotechnology

\section{Introduction}

Imagine a university laboratory inside a museum. Imagine researchers conducting experiments, working on their computers, manipulating instruments and discussing their studies in the midst of a public, noisy and accessible space such as a science museum. Imagine these researchers explaining their research to visitors, doing demonstrations and working during the museum's opening hours. Above all, imagine researchers having to be on display. This is not a far-fetched thought. In fact, an increasing number of museums are currently experimenting with just this move: to put research laboratories inside the museum (usually behind glass walls) and allow visitors a chance to encounter research work. This raises a number of questions and challenges, both practical and theoretical. How is a laboratory transformed during this process? How are the visitor's perceptions of scientific research changed? Does this move actually achieve its desired outcomes? In this paper, I address some of these questions by reporting on a workshop titled 'Open Research: Approaches - Concepts - Perspectives' held at the Deutsches Museum, Munich, in February 2010, and by examining and analysing the museum's 'open research laboratory' - or 'Gläsernes Forscherlabor' in German.

One reason for the focus on the Deutsches Museum is that it may be regarded as a point of reference for this work in Europe. At the time of the workshop, the Deutsches Museum had almost four years of experience with its open research 
laboratory, which has served as a model for setting up further open research laboratories across Europe. In fact, a European Union (EU) project called 'NanoToTouch', has been set up and will run from March 2009 until August 2011, led by the Deutsches Museum. As Hix notes,

The NanoToTouch project aims to create innovative environments for the broad public to learn about and to discuss nanoresearch by directly involving the actors of research themselves. This will be accomplished by taking the laboratory environment and the research work out of the enclosed academic campuses and relocating them right in the midst of the public in science museums and science centres. (Hix 2009, 34)

Building upon the experience of the open research laboratory at the Deutsches Museum, the aim of 'NanoToTouch' is to set up several such open laboratories. At the time of writing, the museums in Milan (Italy) and Gothenburg (Sweden) have just opened theirs and three further 'Nano Researcher Live areas' are due to be installed in science centres in Mechelen (Belgium), Tartu (Estonia) and Naples (Italy).

\section{The workshop}

Paul Hix, a member of staff at the Deutsches Museum, is one of the founders of the open research laboratory. This laboratory carries out and shows 'live' research in the field of nanotechnology. The aim of this laboratory is fivefold: the presentation, explanation, display and discussion of nanotechnology, as well as carrying out research activities. In Hix's view, the challenge for museums is that they usually have static presentations; that they give no sense of everyday scientific work and that the presentation of contemporary equipment found in the typical science museum is usually not very stimulating for visitors. While museums are by and large seen as a place of encounter, of fascination, of neutral information, demonstrations and exhibitions - they are hardly ever seen as a place where people encounter research in the making and where there is room for discussion about the needs, risks and ethical dimensions of science. Such discussions usually happen behind closed doors, just as most laboratory research takes place in enclosed and protected spaces that are rarely open to the public. An increasing number of universities have, of course, come to organise one or two open days per year, where people can visit laboratories. These open days are, however, always limited per year and are not able to handle a great number of visitors. The museum, in contrast, has the potential to show research during the whole year and to attract far higher number of visitors. On the other hand, university open days can be controlled and the number of visitors on the tour can be managed, which museums are less able to do.

So this is the challenge that the Deutsches Museum took up: to move a university laboratory into the museum and to bring these discussions about risk and ethics, and the actual 'doing' of research, into the public domain (discussed in more detail in the second section). In fact, the Deutsches Museum is ideally suited for this, since it is both a classical museum with collections and exhibitions of technical and scientific objects, and a science centre with a focus on experiencing and understanding techno-scientific relationships (Kampschulte 2008, 186).

Another example from the Deutsches Museum (presented by Miriam Voss at the workshop) was a series of video conferences involving laboratories at the nearby 
Ludwig-Maximilians University and organised in the museum. The aim of these biweekly conferences, which have been running since December 2009, is to foster school children's understanding of research and to help them engage in discussions and dialogue with researchers. The potential advantages of the video format are that access can be granted to restricted areas of research laboratories; more people can take part in these events, and these conferences can be combined with visits in the museum. The pupils are encouraged to ask questions of the researchers at these events - which they do, and some of which are surprisingly well articulated, according to Voss.

A different example presented at the workshop by Louise Fitton is the Darwin Centre at the London Museum of Natural History (UK). The main idea here is to broaden and deepen the interaction between the museum and its visitors, and to turn the museum 'inside out' by not only showing what scientists know, but also how they come to know the natural world. The former director of the museum noted that at the Darwin Centre, 'The third strand is to show science in action - to enable visitors to meet the people who do the science, to see what their research involves, and to discuss it with them [...] The Darwin Centre is really a principle perhaps most easily summarised as "Open Up Your Science"' (Chalmers 2004, 281). The Darwin Centre makes it possible for visitors to view laboratories, as well as collection storage space, through glass windows. One of the ideas was to dispel the 'myth of the white coat' and show that scientists are 'normal' people.

For instance, through a glass window - and standing at the same height as the scientists - visitors can see the specimen preparation area of the museum. Although separated by the window, visitors can ask researchers questions through a microphone system (instructions to use the microphone are posted). However, in another part of the exhibition space, the windows that allow visitors to view the research laboratories of the Museum have been designed to avoid the impression of a 'human zoo', where scientists would feel under scrutiny. Here, the floors of the laboratories are not at the same level as the floors on which visitors stand, so the visitor's gaze is allegedly not imposing and scientists do not feel scrutinised by the visitor.

A final example is the open laboratory at the Old Museum in Berlin, which was presented by Stefan Simon. In this museum, an open laboratory was set up between March and June 2009 and research related to the conservation of the museum's artefacts was carried out. The laboratory had a sign saying 'Questions are welcome' on one of its walls. According to Simon, the most frequent questions were about the artefacts the scientists were working on, their jobs, what they studied and how much money they make. In contrast to the examples mentioned earlier, the laboratory in the Berlin Museum could be moved around within the museum itself and allowed the scientists to carry out in situ investigations and restorations of artefacts.

\section{Contextualising the open laboratory}

The four examples discussed earlier are part of wider shifts that have taken place in the world of science museums over the past few decades. There have been shifts in material form, for instance, with an increasing emphasis on interactivity (e.g., Barry 1998; Witcomb 2006), 1 as well as calls to move from a 'conference architecture' towards an 'architecture of interaction' (Yaneva, Rabesandratana, and Greiner 2009), 
where experts and laypeople can more fruitfully communicate and interact. Encounters between visitor and museum have also changed, shifting from being passive and rather immobile, towards other forms of interaction and 'hands-on' exhibits. Lewenstein and Bonney (2004) have advocated a shift from a public understanding of science towards a public understanding of research, while Durant (2004) supports a move towards debating and representing unfinished science. In their assessment of recent shifts, Einsiedel and Einsiedel $(2004,73)$ write:

Today, we observe some traditional museums changing into a modern-day museum agora, a public meeting place where citizens seek to discuss and understand scientific research and technological innovations as well as to learn about contentious issues and public policies that are associated with some of them [...] These changes include changing conceptions of their audiences and how to interact with them.

These wider changes also affect the museum object, which moves from being an object of celebration towards something more ambiguous and 'messy' (Meyer 2010). In turn, the science museum becomes a place that is more about science in the making, rather than science already done, and the act of developing a 'laboratory-inthe-museum' has to be situated and analysed within these wider trends. In comparison with a classical scientific display, the laboratory-in-the-museum exemplifies two kinds of shifts: from a display that answers to a display that allows for questions, and from an exhibition that represents existing matters to an exhibition that performs, creates and experiments with new ones (Macdonald 2009; Meyer 2010).

\section{The open research laboratory at the Deutsches Museum}

Returning to the Deutsches Museum, at first sight their open research laboratory looks like a 'normal' laboratory (see Figure 1). There is scientific equipment on the benches, such as a scanning-tunnelling microscope, computers, chairs and desks. There are also researchers, and experiments are being carried out. Hix explained that when setting up the laboratory in collaboration with the Ludwig-Maximilians University in Munich,2 the researchers only moved instruments from the university that were deemed essential for running the laboratory. The laboratory measures 10 by 3 metres and is separated from the public by a glass wall that measures 1.2 metres, 'which clearly defines the laboratory area whilst at the same time enabling the visitors to observe the daily work of the scientists' (Hix 2009, 9). Two-thirds of the laboratory is dedicated to research activities and one-third to demonstration activities. There is a similar separation between the roles and activities of researchers and the so-called 'experimentators', who are mainly concerned with developing and providing demonstrations (Pfuhl and Lewalter 2008, 5). These demonstrations are deemed important to better explain nanotechnology and to allow for comparisons between the nanoworld and the world known to visitors.

A number of things changed as the laboratory was moved to the museum. In a handbook produced by Hix that contains guidelines for setting up an open research laboratory, there is mention of 'presentation aids', 'additional elements' and that 'scientists work is supplemented by a variety of elements'. In order to communicate the challenges and ideas around setting up a laboratory-in-the-museum, the handbook advises: that visitors remember experience, not details; that people should 

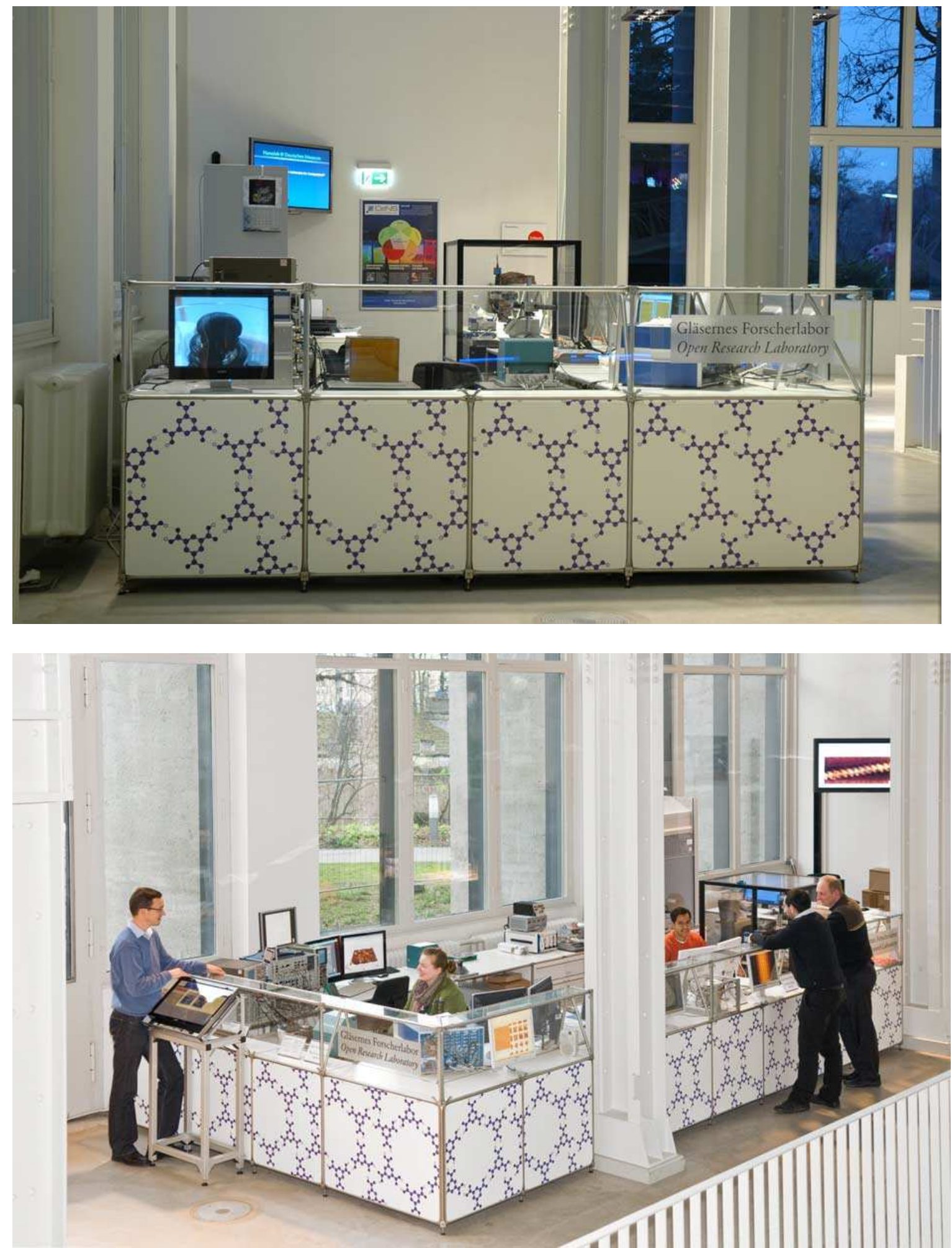

Figure 1. The open research laboratory ('Gläsernes Forscherlabor') at the Deutsches Museum (Photo: copyright Deutsches Museum).

only work for a limited time in the laboratory (i.e., 3-6 months); that career young people (PhDs up to postdocs) should work in the laboratory; that it should be a small research lab (with five to eight scientists); and that it should have a private entrance and a 'quiet room' for reading and holding meetings. 
Monitors have also been duplicated to enable visitors to see what the researchers see on their computer screens (Hix 2009, 15). Further elements that were needed include: a glass wall to separate the laboratory and the visitor, large video screens, demonstration objects, information boards, posters, leaflets and flyers. Clearly, the laboratory-in-the-museum has to deal with a new, 'extended' object-world, and I use the word object in a broad sense here to denote all the artefacts, equipments, models, signs, etc. present in the laboratory. Not only are objects required that enable researchers to carry out scientific work, such as various kinds of instruments and equipment, but there is also a need for objects that engage the visitor - i.e., objects that catch the interest of visitors and encourage them to approach, discuss and debate with the researchers. In effect, this laboratory is populated by objects that perform work (like a microscope), objects that display and explain work (like models used for demonstrations), and objects that focus and frame attention on the performance and explanation of work (posters and information boards, signs). Of course, one object might play several of these roles at the same time and, on occasion, there might be a clash when the object-as-display is the object-asinstrument that is actually used.

The postdoc who currently runs the open research laboratory (Frank Trixler) sometimes has to remind the visitors that what they see 'is not a model, but a real microscope'. Visitors might be surprised to see objects that are used to perform work in an institution that usually displays 'dead' objects - that is, objects that have been removed from commodity circuits, working contexts and practical use. Some visitors also reported being surprised by the fact that everything was indeed 'open', whereas they expected to see a closed room where scientists would be working and that they would only be allowed to observe this room (Pfuhl and Lewalter 2008, 75).

Apart from these object-centred issues, there are also challenges for researchers and visitors. The challenges for the researchers who work in the open research laboratory are many: they have to be 'on display'; they have to work within museum opening hours; they have to cope with a certain level of noise and they are not working inside their university for a certain period. There are also challenges in terms of motivation, rewards and credits, and it is not always easy to motivate and recruit people to work in the museum, partly because of existing reward systems. The issue of people getting credits for carrying out and being trained in communication activities, in addition to their research work, is currently being discussed at the university level.

Challenges also lie in communication between the researchers and the visitors. In the museum, researchers not only interact with peers, but also with a varied audience, which means that they have to explain their research to laypeople and thus restrict their use of scientific terms. According to the director of the Deutsches Museum, PhD students working in the open research laboratory learn two things: that people other than their peers are actually interested in their research and how to communicate with visitors (Heckl 2008). As a result, they not only have to focus on scientific experiments, but they also have to try to create an experience for visitors, which often means initiating discussions with them. Some report that it can be difficult to engage visitors who still see and feel the distance between themselves and the researchers.

Instilling a proactive attitude in visitors and getting them to ask questions is thus anything but easy. This resonates with the suggestion that the public is not yet 
comfortable enough to explore new methods of science communication, [...] i.e., to stroll, to ask questions to the presenters, to engage in communication, to question [...] to look behind the scenes' (Yaneva, Rabesandratana, and Greiner 2009, 86). Also, some visitors reportedly do not 'dare to disturb' the researchers (Pfuhl and Lewalter 2008, 53). On the other hand, researchers themselves might feel uneasy with the idea of having to be on display at all times. This is why the museum came up with the idea of the 'Quiet Room', described in the following terms:

If possible, ensure that the scientists have an additional office room away from public view. This would act both as a 'quiet area', where the researchers can retreat from the visitors for a short time if necessary, as well as providing additional work space in a more peaceful environment. This factor is especially important as some tasks such as writing or literature research are difficult to conduct when there is a lot of background noise. In an office away from public view it would also be possible to conduct internal discussions and group meetings that would otherwise disturb ongoing measurements or presentations in the Open Research Laboratory. However, as these tasks are also fundamental elements of research, the scientists working in the laboratory should be encouraged to perform as many of these processes as possible in public view, retiring to the private office only when absolutely necessary. (Hix 2009, 29)

Hence, not everything that scientists do is to be visible and displayed to the visitors, and there is a boundary drawn between the protected and private Quiet Room and the noisy, public space of the museum.

Actually, a substantial part of researchers' work takes place outside a laboratory, such as attending and presenting at conferences, meeting colleagues in other laboratories, teaching, reading, etc. Pels further argues that:

Despite the recent avalanche of social interpretations, practising science (including social science) is still much more a matter of non-verbal, solitary (if not solipsistic) interaction with non-human objects (such as books, articles, protocols, instruments, machines, pen and paper, keyboard and screen) in the comparative stillness of one's study or laboratory than a matter of talking to and negotiating with other human subjects. (Pels 2003, 214)

Even inside a laboratory, a great part of research activity tends to be invisible and solitary, such as the thinking, planning and analysing involved in any knowledge production (L. Garforth, pers. comm.). Also, it is important to stress that nanotechnology is very much a laboratory-based science and a lot of data production and analysis take place within the confines of the laboratory. For other sciences, such as archaeology, botany, anthropology and sociology, for example, this is not necessarily the case. These sciences are much more field-based and much observation, empirical data collection and even writing take place outside of the laboratory. This poses an even bigger challenge for such sciences when they are displayed in a museum. Hence, beyond the mere practical aspect of moving a university research laboratory into a public space, a crucial question for museums is: What kinds of, and parts of, scientific research can and should be displayed in a museum?

Some environmental sciences, such as ecology, could be an interesting topic for science museums to also consider. As a science concerned with social issues and the natural environment, ecology might provide a fruitful starting point for visitors to reflect upon socio-economic and environmental problems and issues of 
sustainability, and therefore help them to become more engaged and critical citizens (see Worts 2006). This, therefore, could not only facilitate the move from a public understanding of science, to a public understanding of research (the now common argument for science museums and much academic writing), but also potentially facilitate a more far-reaching move toward a "critical understanding of the politics of research'.

\section{Final considerations}

It is difficult to display processes and human activities in a museum (Lewenstein and Bonney 2004, 65), especially science in the making (Arnold 1996). The challenge with the laboratory-in-the-museum means a move from 'object lessons' (see Schaffer 2000) to 'practice lessons', and from an experience based upon gaze - with a separation and demarcation between the visitor and a 'flat' museum object - to one that is far more spatial, dialogical, interactive and corporal. Seeing, reading and discussing a laboratory means encountering a three-dimensional and ordered setting, occupied by instruments and researchers in which people, objects and ideas move. However, instead of ending at its glass walls, this three-dimensional setting caters to and is oriented towards the visitors - it allows them to see, to observe, to interact, to react and to question. In a sense, it is a setting designed to allow for discussions 'over the counter' (in this case a 1.2-metre glass wall). Hence, the laboratory-in-themuseum does not only represent and display a particular kind of space, but also creates and is constantly recreating a space for dialogue and discussion between researchers and visitors.

Displaying the laboratory and, at the same time, creating a space for discourse about science inside a museum certainly has transformative potential. For some visitors and researchers this move might improve, disturb, question or destabilise 'normal' practices, as much as it disturbs current research practices and cultures inside the universities that take part in these experiments. The laboratory-in-themuseum holds the potential to foster an interrogative approach by visitors, as it puts onstage research settings, research instruments, researchers in action, researchers' explanations of their work and their motivations. For researchers, the laboratory-inthe-museum redraws the lines between essentially private and public space, between scientific research and science communication and between experiment and experience.

The museum, as a public space able to bring research and the public together, is arguably a good place to open up the laboratory. In contrast to 'universities and research institutes [which] are atmospheres where anyone, except scientists, feels inhibited' (Wagensberg 2000, 138), museums tend to be more open, accessible and democratic. Museums can thus provide a space of encounter where professionals and amateurs, scientists and children and experts and laypeople can meet, discuss and learn. Museums also have a long tradition of credible public service; they are more welcoming than the elite university; they are physically accessible and have public-oriented facilities, and they can act as a mediator between publics and experts - to the point where some have started to hold consensus conferences and inquirybased learning activities (Einsiedel and Einsiedel 2004, 80-1, see also Chittenden 2011). 
Durant has pressed the point and argued that a new role for science museums lies in facilitating public engagement with research (Durant 2004, 59). The role that the laboratory-in-the-museum can play to foster this is certainly an issue that needs further research. In particular, the limits of such engagements must be further examined. The examples discussed in this paper revealed a rather 'photographic approach', in that displays were 'bounded, glass-covered, to be viewed (never touched)' (Jenkins 1994, 246). There was still a glass wall that separated the laboratory world from the visitor world. While the interactions between these two worlds were visual and discursive, visitors were not allowed to enter the laboratory space or to interact in a 'hands-on' manner with objects. Hence, while putting a research laboratory behind a glass wall and into a museum certainly opens up research work to visitors, it does not eradicate the cognitive distance that exists between researchers and the public - nor does it turn visitors into researchers. The educational value of such settings thus needs to be further analysed and compared to similar settings in other museums.

Some preliminary information about the visitors' experience can, however, be taken from a report about the open research laboratory that the Deutsches Museum published in 2008 (Pfuhl and Lewalter 2008). Although visitors said that they already knew what a research laboratory looked like (having either seen one on television or having already visited one), they had imagined it differently and expected more instruments, fewer computers and a bigger and a more spectacular setting. Yet, all in all, the majority of the visitors reported to have liked the discussions they had very much and they commented positively on the comprehensiveness of the explanations given (Pfuhl and Lewalter 2008, 53). They mentioned a positive learning experience; that they were now able to say what nanotechnology is concerned with and how nanotechnology research is being carried out, and that they wish to know more about nanotechnology in the future (Pfuhl and Lewalter 2008, 54).

Yet, the report also notes that visitors did not seem to have experienced their visit to the open research laboratory as a real 'dialogue'. When being asked what their visit made them think of, 26 schoolchildren said they felt the discussion resembled a 'situation at school', 14 thought it looked like a 'presentation/monologue', and 6 referred to it as an 'informative scientific event'. This clearly contrasts to only two persons describing it as a 'situation of discussion after a lecture', and one other referring to it as a 'round of research in-between friends'. Despite the museum's intent to create a dialogical and interactive space between researchers and visitors, the question remains to what extent visitors experience it as such. Displaying research settings, research instruments, researchers and providing encounters to discuss researchers' work and motivations do not necessarily mean a levelling of power and expertise between the museum and researchers, and visitors. Visitors are supposed to learn and ask questions about nanotechnology without, however, being allowed to engage and participate in actual research work. In the museum, visitors are still positioned as laypeople and as receivers, rather than as producers of knowledge.

Last, it is common to argue in the history of science that the museum used to be the characteristic locus of scholarship and research until the nineteenth century but that, over time, laboratories came to displace this role (Forgan 1994). Of course, the laboratory has not eclipsed the museum; rather it has supplemented it (Kraft and Alberti 2003), and there are still continuities between the museum and laboratory 
traditions. To put it another way, museums and laboratories are 'equal though different' (Kraft and Alberti 2003). One of the key differences is arguably the distance between the expert and the layperson, and between science and the public. The history of most sciences is that of an extreme confinement that ultimately sets laboratories and instruments out of reach of the amateur and the layperson (Callon, Lascoumes, and Barthe 2001, 65). The requirement for precise measurements and the elimination of interferences have made it necessary for experiments to be done in a private and confined space (Callon, Lascoumes, and Barthe 2001, 72). Today's laboratory is spatially and socially organised in ways that make it a highly demarcated, protected, confined and disciplined space. Moving the laboratory into the museum is therefore an interesting and potentially counter-intuitive move, since most movements have been in the opposite direction throughout the history of science. With this article I have attempted to point out some issues that arise when the laboratory is 'spatially challenged' by being put into a museum. As we have seen, its spatial layout, its staff and its objects are transformed and reorganised as a result.

Putting research and researchers on display inside a museum means rethinking and reorganising the laboratory's material and social architecture. It entails setting up an experimental space for knowledge production; substituting opaque walls with transparent ones and extending the laboratory's object-world to accommodate objects that perform, display, explain and focus attention on work. Last but not least, it means creating and signposting a space to discuss and interact with visitors. Perhaps the crucial issue is to find a balance between setting up a space that is not confined - that reduces the distance between experts and laypeople and that opens up private spaces to public view and public debates - and ensuring that this setting caters to a legitimate, productive and robust knowledge production.

\section{Notes on contributor}

Morgan Meyer has a postdoctoral appointment at the Centre for the Sociology of Innovation at the Ecole des Mines de Paris (MINES ParisTech). He holds a PhD from the Department of Sociological Studies at the University of Sheffield, UK. His PhD work explored the co-production of knowledge by amateurs and professionals in a museum of natural history. His research interests include the sociology and geography of science; knowledge brokering; boundaries and boundary-work; actornetwork theory; epistemic communities; museum studies; and science and culture in Luxembourg.

\section{Acknowledgements}

I would like to thank Brice Laurent and Ariane Debourdeau for their comments and to Peter Schüssler, Paul Hix and Helmut Trischler for the invitation. Thanks to all the participants of the workshop at the Deutsches Museum without whom this paper would not have come to exist. Last, but not least, I would like to thank three anonymous referees for their excellent feedback. A translated, abridged and revised version of this article has also been published (Meyer and Schüssler 2011).

\section{Notes}

1. An enthusiasm for interactivity and engagement with research is not unique to the twenty-first century, having arrived in Europe in the mid-1980s (Barry 1998).

2. The Deutsches Museum is involved in partnerships with both universities in 
Munich: it is a strategic partner of the Technische Universität München for publicising research in the frame of the latter's 'TUM. The Entrepreneurial University' programmes, and it is involved in the 'Nanosystems Initiative München' together with the Ludwig-Maximilians University (Kampschulte 2008, 186-7). The overall idea of these initiatives is not only to display current research but also to bring together three interest groups: science, policy and the public (Kampschulte 2008). This raises further questions about the nature and practicalities of the partnerships between the university and the museum when setting up such programmes. Issues about funding and costs, about the limits and problems that arise in these cases, about the productivity of laboratories and possible incentives to enrol researchers, etc. are at stake. While these issues are certainly important ones, it is beyond the scope of this article to explore them in more detail.

\section{References}

Arnold, Ken. 1996. Presenting science as product or as process: Museums and the making of science. In Exploring science in museums, Susan Pearce, 57-78. London : Athlone.

Barry, Andrew. 1998. On interactivity: Consumers, citizens and culture. In The politics of display: Museums, science, culture, Sharon Macdonald, 98 - 117. London : Routledge.

Callon, Michel, Lascoumes, Pierre and Barthe, Yannick. 2001. Agir dans un monde incertain. Essai sur la démocratie technique, Paris: Seuil.

Chalmers, Neil. 2004. Public understanding of research in a natural history museum: The Darwin centre. In Creating connections. Museums and the public understanding of current research, David Chittenden, Graham Farmelo, and Bruce Lewenstein, 276 88. Walnut Creek : AltaMira Press.

Chittenden, David. 2011. Commentary: Roles, opportunities, and challenges-science museums engaging the public in emerging science and technology. Journal of Nanoparticle Research, 13: 1549-1556.

Durant, John. 2004. The challenge and the opportunity of presenting 'unfinished science'. In Creating connections. Museums and the public understanding of current research, David Chittenden, Graham Farmelo, and Bruce Lewenstein, 47 - 60. Walnut Creek: AltaMira Press.

Einsiedel, Albert, and Edna Einsiedel. 2004. Museums as agora: Diversifying approaches to engaging publics in research. In Creating connections. Museums and the public understanding of current research, David Chittenden, Graham Farmelo, and Bruce Lewenstein, 73 - 86. Walnut Creek : AltaMira Press.

Forgan, Sophie. 1994. The architecture of display: Museums, universities and objects in nineteenth-century Britain. History of Science, 32(6): 139-62.

Heckl, Wolfgang. 2008. Das Gläserne Forscherlabor. Sb Science Blogs. http://www.scienceblogs.de/deutsches-museum/2008/02/das-glaserne-forscherlaborim-deutschen-museum.php

Hix, Paul. 2009. Professional guidelines for establishing an open nano lab/a nano researcher live are, Handbook, Munich: Deutsches Museum.

Jenkins, David. 1994. Object lessons and ethnographic displays: Museum exhibitions and the making of American anthropology. Comparative Studies in Society and History, 36(2): $242-70$.

Kampschulte, Lorenz. 2008. Nano-Kommunikation-Strategien zur Förderung einer realistischen öffentlichen Wahrnehmung der Nanotechnologie. In Nano(bio)technologie im öffentlichen Diskurs, Roger Busch, 179 - 91. Munich: 
Herbert Utz Verlag.

Kraft, Alison and Alberti, Sam. 2003. Equal though different: Laboratories, museums and the institutional development of biology in Late-Victorian Northern England. Studies in the History and Philosophy of Biological and Biomedical Sciences, 34: 203-36.

Lewenstein, Bruce, and Rick Bonney. 2004. Different ways of looking at public understanding of research. In Creating connections. Museums and the public understanding of current research, David Chittenden, Graham Farmelo, and Bruce Lewenstein, 63 72. Walnut Creek : AltaMira Press.

Macdonald, Sharon. 2009. Exhibition experiments: Publics, politics and scientific controversy. In Exposer des idées, questionner des savoirs. Les enjeux d'une culture de sciences citoyennes, ed. Roger Gaillard, 195-204. Neuchâtel: Editions Alphil.

Meyer, Morgan. 2010. From 'cold' science to 'hot' research: The texture of controversy. In Hot topics, public culture, museums, ed. Fiona Cameron and Lynda Kelly, 129-49. Newcastle : Cambridge Scholars.

Meyer, Morgan, and Peter Schüßler. 2011. Le laboratoire 'en verre': Exposer la science en action au musée. Hermès, 61: 185-187.

Pels, Dick. 2003. Unhastening science. Temporal demarcations in the 'social triangle'. European Journal of Social Theory, 6(2): 209-31.

Pfuhl, Nadja and Lewalter, Doris. 2008. Abschlussbericht: Studie zum Ausstellungsbereich Gläsernes Forscherlabor, Munich: Technische Universität München.

Schaffer, Simon. 2000. Object lessons. In Museums of modern science, ed. Savante Lindqvist, $61-76$. Canton : Watson.

Wagensberg, Jorge. 2000. In favour of scientific knowledge: The new museums. In Museums of modern science, ed. Savante Lindqvist, 129 - 38. Canton : Watson.

Witcomb, Andrea. 2006. Interactivity: Thinking beyond. In A companion to museum studies, ed. Sharon Macdonald, $353-61$. London : Blackwell.

Worts, Douglas. 2006. Fostering a culture of sustainability. Museums \& Social Issues, 1(2): 151-72.

Yaneva, A., Rabesandratana, T.M. and Greiner, B. 2009. Staging scientific controversies: A gallery test on science museums' interactivity. Public Understanding of Science, 18(1): 79-90. 